\title{
Ultrasound-Guided Thrombin Injection in the Treatment of Femoral Artery Pseudoaneurysm after Percutaneous Procedures in Patients with Acute Coronary Syndrome
}

\author{
Fábio Augusto Pinton ${ }^{1}$, Alexandre Russo Spósito², Vitor de Andrade Vahle ${ }^{3}$, Paulo Rogério Soares ${ }^{4}$, \\ Silvio Zalc ${ }^{5}$, Marco Antonio Perin ${ }^{6}$, Expedito Eustáquio Ribeiro da Silva \\ Antonio Esteves Filho ${ }^{8}$, Pedro Alves Lemos Neto ${ }^{9}$
}

\begin{abstract}
Background: Ultrasound-guided thrombin injection (TI) is an option for the treatment of femoral artery pseudoaneurysm. Nevertheless, the result of this technique in patients with acute coronary syndrome (ACS) may be compromised by the use of antithrombotic drugs. In addition, thrombin extravasation to systemic circulation could potentially cause an increase in thromboembolic events. Methods: Patients admitted with ACS who developed femoral artery pseudoaneurysm after a percutaneous procedure and treated by TI between January 2007 and July 2011 were included. Clinical and laboratory characteristics, treatment results and complications were evaluated. Results: We evaluated 23 patients with mean age of 67.1 \pm 14.2 years, $60.9 \%$ were women, with body mass index of $28.4 \pm 4.7 \mathrm{~kg} / \mathrm{m}^{2}$ and $52.2 \%$ were diabetics. At presentation, $87 \%$ had non-ST elevation ACS and the remaining had ST elevation myocardial infarction. Of the evaluated patients, $70 \%$ were submitted to percutaneous coronary intervention. All patients were receiving aspirin, $78.3 \%$ used P2Y12 inhibitors and $39.1 \%$ used glycoprotein Ilb/llla inhibitors. TI was successful in occluding the pseudoaneurysm in $100 \%$ of cases (96.7\% after the first injection), without distal embolization, local infection or need of surgical correction. There were no cases of myocardial infarction, stroke or unscheduled revascularization. There was one death due to cardiogenic shock
\end{abstract}

\section{RESUMO}

\author{
Injeção de Trombina Guiada por Ultrassom \\ no Tratamento de Pseudoaneurisma da Artéria \\ Femoral após Procedimento Percutâneo \\ em Pacientes com Síndrome Coronária Aguda
}

\begin{abstract}
Introdução: A injeção de trombina guiada por ultrassom (IT) é uma opção para o tratamento de pseudoaneurisma da artéria femoral. No entanto, o resultado dessa técnica em pacientes com síndrome coronária aguda (SCA) pode ser comprometido pelo uso de medicações antitrombóticas. Também, o extravasamento de trombina para a circulação sistêmica pode causar aumento de eventos tromboembólicos. Métodos: Foram selecionados todos os pacientes admitidos com SCA que apresentaram pseudoaneurisma da artéria femoral após procedimento percutâneo, tratados com IT, entre janeiro de 2007 e julho de 2011. Características clínicas e laboratoriais, resultado do tratamento e complicações foram avaliados. Resultados: Analisamos 23 pacientes, com idade de $67,1 \pm 14,2$ anos, $60,9 \%$ eram do sexo feminino, com índice de massa corporal de $28,4 \pm 4,7 \mathrm{~kg} / \mathrm{m}^{2}$, e $52,2 \%$ eram diabéticos. À apresentação, $87 \%$ tinham SCA sem supradesnivelamento do segmento ST e o restante, infarto do miocárdio com supradesnivelamento do segmento ST. Entre os pacientes avaliados, $70 \%$ foram submetidos a intervenção coronária percutânea. Todos os pacientes estavam em uso de
\end{abstract}

\footnotetext{
Resident physician at the Invasive Cardiology Service of Instituto do Coração do Hospital das Clínicas da Faculdade de Medicina da Universidade de São Paulo. São Paulo, SP, Brazil.

2 Resident physician at the Invasive Cardiology Service of Instituto do Coração do Hospital das Clínicas da Faculdade de Medicina da Universidade de São Paulo. São Paulo, SP, Brazil.

${ }^{3}$ Resident physician at the Invasive Cardiology Service of Instituto do Coração do Hospital das Clínicas da Faculdade de Medicina da Universidade de São Paulo. São Paulo, SP, Brazil.

${ }^{4}$ Doctor. Cardiologist physician at the Invasive Cardiology Service of Instituto do Coração do Hospital das Clínicas da Faculdade de Medicina da Universidade de São Paulo. São Paulo, SP, Brazil.

${ }^{5}$ Doctor. Cardiologist physician at the Invasive Cardiology Service of Instituto do Coração do Hospital das Clínicas da Faculdade de Medicina da Universidade de São Paulo. São Paulo, SP, Brazil.

${ }^{6}$ Full professor. Interventionist cardiologista physician at the Invasive Cardiology Service of Instituto do Coração do Hospital das Clínicas da Faculdade de Medicina da Universidade de São Paulo. São Paulo, SP, Brazil.
}

7 Full professor. Interventionist Cardiologist at the Invasive Cardiology Service of Instituto do Coração do Hospital das Clínicas da Faculdade de Medicina da Universidade de São Paulo. São Paulo, SP, Brazil.

${ }^{8}$ Interventionist cardiologist physician at the Invasive Cardiology Service of Instituto do Coração do Hospital das Clínicas da Faculdade de Medicina da Universidade de São Paulo. São Paulo, SP, Brazil. ${ }^{9}$ Full professor. Director of Invasive Cardiology Service of Instituto do Coração do Hospital das Clínicas da Faculdade de Medicina da Universidade de São Paulo. São Paulo, SP, Brazil.

Correspondence to: Fábio Augusto Pinton. Av. Dr. Enéas Carvalho de Aguiar, 44 - Cerqueira César - São Paulo, SP, Brazil - CEP 05403-900 E-mail: fabiopinton@gmail.com

Received on: 2/1/2013 • Accepted on: 28/2/2013 
22 days after $\mathrm{TI}$, on the second post-operative day after an elective coronary artery bypass graft surgery. Conclusions: Treatment of femoral artery pseudoaneurysm by $\mathrm{TI}$ is a safe and effective procedure in patients with ACS.

DESCRIPTORS: Cardiac catheterization. Thrombin. Ultrasonography, interventional. Acute coronary syndrome.

$\mathrm{T}$ he occurrence of femoral artery pseudoaneurysm after heart catheterisation has an incidence between $0.05 \%$ and $2 \%$, increasing to $3 \%$ to $8 \%$ in therapeutic procedures, due to the use of larger caliber sheaths, as well as more potent antiplatelet and anticoagulant therapies, especially in patients with acute coronary syndrome. ${ }^{1-4}$

The three main forms of treatment for this type of complication are surgical correction, ultrasound-guided compression, and thrombin injection (TI).

Traditionally, the surgical approach has been considered the reference standard; however, due to its invasive characteristic, it is associated with a higher rate of complications and wound infection, bleeding, and wound dehiscence. Moreover, it is also associated with a longer in-hospital stay and higher costs. ${ }^{5,6}$

In the early 1990s, ultrasound-guided compression was introduced by Fellmeth et al. ${ }^{7}$ as one of the first non-invasive methods for pseudoaneurysm correction. Its advantages are the fact that it is noninvasive and low cost, but most of the time, prolonged compression is necessary to achieve success. Many patients do not tolerate it due to the pain, and it is less effective, especially in the context of acute coronary syndromes. ${ }^{8,9}$

Recently, TI has become the method of choice in the treatment of this complication. ${ }^{10}$ Several studies, both Brazilian and international, have shown high success rates when using thrombin for femoral artery pseudoaneurysm correction. ${ }^{11-15}$ However, few data are currently available on the safety and efficacy of local thrombin use in patients with acute coronary syndrome. In this population, it is speculated that the frequent use of anticoagulants and antiplatelet agents could reduce the technique effectiveness. Conversely, any thrombin extravasation into systemic circulation could determine an increase in adverse events in this subgroup of patients at higher atherothrombotic risk. ácido acetilsalicílico, 78,3\% utilizaram inibidores da $\mathrm{P} 2 \mathrm{Y}_{12}$ e $39,1 \%$, inibidores da glicoproteína IIb/IIla. A IT foi eficaz em ocluir o pseudoaneurisma em $100 \%$ dos casos $(96,7 \%$ após a primeira injeção), sem embolia distal, infecção local ou necessidade de correção cirúrgica em nenhum caso. Não houve infarto, acidente vascular cerebral ou revascularização não-programada. Houve um óbito por choque cardiogênico, 22 dias após a IT, no segundo dia após cirurgia eletiva de revascularização miocárdica. Conclusões: O tratamento de pseudoaneurisma da artéria femoral com IT é um método seguro e eficaz em pacientes com SCA.

DESCRITORES: Cateterismo cardíaco. Trombina. Ultrassonografia de intervenção. Síndrome coronariana aguda.

This study aimed to evaluate the clinical performance of ultrasound-guided $\mathrm{TI}$ in patients with acute coronary syndrome who developed femoral artery pseudoaneurysm after percutaneous procedure.

\section{METHODS}

All patients with femoral artery pseudoaneurysm after diagnostic or therapeutic heart catheterisation due to acute coronary syndrome (unstable angina, acute coronary syndrome without ST-segment elevation [ACSWSTE], and myocardial infarction with ST-segment elevation [STEMI]), treated with ultrasound-guided $\mathrm{TI}$ at the Instituto do Coração of Hospital das Clínicas da Faculdade de Medicina of Universidade de São Paulo (São Paulo, SP, Brazil), from January 2007 to July 2011 were selected through electronic medical record analysis.

The arterial sheath was removed by manual compression for at least 15 minutes, six hours after the administration of unfractionated heparin or ten to 12 hours after the last administration of low molecular-weight heparin. After a local pressure dressing was applied, the patient remained on bed rest, with lower-limb movement restriction for at least six hours after sheath removal.

The pseudoaneurysm diagnosis was attained by clinical examination (presence of painful, pulsatile hematoma, with murmur) and confirmed with Doppler ultrasound. The decision for pseudoaneurysm treatment with thrombin was made at the attending physician's discretion.

All TI procedures were performed by a team of interventional radiology professionals at this institution. After thrombin administration and confirmation of flow absence, local pressure dressing was applied and the patient remained at rest for 24 hours.

Method effectiveness was assessed by procedural success, defined by flow absence within the pseudoaneurysm after TI. 
The presence of complications during hospitalisation was assessed for the safety analysis, and was defined by distal embolism in the treated limb, local infection, need for surgical correction, need for transfusions, acute myocardial infarction, stroke, new unplanned revascularisation after the index procedure, and death.

Data on clinical, laboratory characteristics, medications used, effectiveness, and safety of the procedure were collected in electronic medical records.

\section{RESULTS}

Of the 31 patients who developed pseudoaneurysm of the femoral artery after catheterisation and/or percutaneous coronary intervention and were treated by ultrasound-guided $\mathrm{TI}, 23$ had a diagnosis of acute coronary syndrome and were considered for the analysis.

The majority were female $(60.9 \%)$, aged $67.1 \pm 14.2$ years (32.6 years to 92.8 years), with body mass index $=28.4 \pm 4.7 \mathrm{~kg} / \mathrm{m}^{2}$. Systemic arterial hypertension was present in $91.3 \%$ of the patients, diabetes in $52.2 \%$, $17.4 \%$ were smokers, and $30.4 \%$ had heart failure. A third of the population had undergone previous percutaneous coronary intervention and $8.7 \%$ had been submitted to myocardial revascularisation.

Hemoglobin and hematocrit values at the time of the percutaneous procedure were $12.4 \pm 2.1 \mathrm{mg} / \mathrm{dL}$ and $37.9 \pm 6.3 \%$, respectively. Mean creatinine clearance, calculated by the Cockroft and Gault formula, was $62.1 \pm 34.5 \mathrm{~mL} / \mathrm{min}$. All patients were receiving acetylsalicylic acid, $78.3 \%$ used $\mathrm{P}_{2} \mathrm{Y}_{12}$ inhibitors, $39.1 \%$ used glycoprotein Ilb/IIla inhibitors, $65.2 \%$ used low molecular weight heparin, and $17.4 \%$ used unfractionated heparin. Only one patient $(4.3 \%)$ received thrombolytic therapy (Table 1).

Regarding the clinical picture, $87 \%$ of patients had a diagnosis of unstable angina or ACSWSTE, and the remainder had a diagnosis of STEMI. Diagnostic catheterisation was performed in $30.4 \%$ and therapeutic procedure in $69.6 \%$ of cases. The $7 \mathrm{~F}$ sheath was used in $73.9 \%$ of procedures and $6 \mathrm{~F}$ in the remainder.

The mean time from the percutaneous procedure to the pseudoaneurysm diagnosis was $2.7 \pm 2.5$ days (median $=2$ days), and until the ultrasound was performed, $3.2 \pm 0.8$ days. Pseudoaneurysm neck size ranged from $0.2 \mathrm{~cm}$ to $3.7 \mathrm{~cm}$ (mean $0.9 \pm 1 \mathrm{~cm}$ ), and the largest diameter ranged from $1.3 \mathrm{~cm}$ to $6 \mathrm{~cm}$ (mean $2.7 \pm 1.8$ $\mathrm{cm})$; they were multiloculated in $17.4 \%$ of patients.

Procedural success was achieved in $96.7 \%$ of patients with the first $\mathrm{TI}$ and in $100 \%$ with the second procedure (performed 48 hours after the first attempt). Most patients $(78.3 \%)$ were receiving dual antiplatelet therapy and more than half $(56.5 \%)$ used prophylactic heparin during the procedure to repair the pseudoaneurysm. There were no reports of distal embolic
Table 1

Clinical and laboratory characteristics of patients

$\mathrm{n}=\mathbf{2 3}$

\begin{tabular}{|c|c|}
\hline \multicolumn{2}{|l|}{ Clinical characteristics } \\
\hline Male gender, n (\%) & $9(39,1)$ \\
\hline Age, years & $67.1 \pm 14.2$ \\
\hline Body mass index, kg/m² & $28.4 \pm 4.7$ \\
\hline Systemic arterial hypertension, n (\%) & $21(91.3)$ \\
\hline Diabetes mellitus, n (\%) & $12(52.2)$ \\
\hline Dyslipidaemia, n (\%) & $17(73.9)$ \\
\hline Current smoking, n (\%) & $4(17.4)$ \\
\hline Previous infarction, n (\%) & $5(21.7)$ \\
\hline Heart failure, n (\%) & $7(30.4)$ \\
\hline $\begin{array}{l}\text { Previous percutaneous coronary } \\
\text { intervention, } \mathrm{n}(\%)\end{array}$ & $8(34.8)$ \\
\hline Myocardial revascularisation, n (\%) & $2(8.7)$ \\
\hline \multicolumn{2}{|l|}{ Laboratory characteristics } \\
\hline Creatinine clearance, $\mathrm{mL} / \mathrm{min}$ & $62.1 \pm 34.5$ \\
\hline Hemoglobin, mg/dL & $12.4 \pm 2.1$ \\
\hline Hematocrit, \% & $37.9 \pm 6.3$ \\
\hline \multicolumn{2}{|l|}{ Clinical picture } \\
\hline $\begin{array}{l}\text { Acute coronary syndrome without } \\
\text { ST-segment elevation }\end{array}$ & $20(87)$ \\
\hline $\begin{array}{l}\text { Myocardial infraction with } \\
\text { ST-segment elevation }\end{array}$ & $3(13)$ \\
\hline \multicolumn{2}{|l|}{ Periprocedural drug therapy, n (\%) } \\
\hline Acetylsalicylic acid & $23(100)$ \\
\hline $\mathrm{P} 2 \mathrm{Y}_{12}$ inhibitors & $18(78.3)$ \\
\hline Glycoprotein Ilb/IIla inhibitors & $9(39.1)$ \\
\hline Low molecular-weight heparin & $15(65.2)$ \\
\hline Unfractionated heparin & $4(17.4)$ \\
\hline Thrombolytic therapy & $1(4.3)$ \\
\hline
\end{tabular}

complications, allergic reactions, local infection, need for surgical correction, need for blood products or acute myocardial infarction, stroke, and new revascularisation after the index procedure.

There was one death among the study population due to cardiogenic shock, on the second postoperative day after elective myocardial revascularisation, 22 days after TI. 


\section{DISCUSSION}

Pseudoaneurysm after percutaneous heart procedures is one of the most common vascular complications. The main risk factors for its occurrence are age $>65$ years, hypertension, obesity, peripheral arterial disease, large calibre sheaths, and use of antiplatelet and anticoagulant agents. ${ }^{10}$ In the present sample, the mean age was 67.1 years; $91.3 \%$ were hypertensive; $73.9 \%$ used $7 \mathrm{~F}$ sheaths, and $69.6 \%$ were receiving dual antiplatelet therapy associated with heparin at a therapeutic dose.

Until 1990, the only available treatment for pseudoaneurysm was surgical correction. Although very effective, this procedure can present several complications. San Norberto García et al. ${ }^{16}$ studied 79 patients who underwent surgery for pseudoaneurysm repair. In this study, $71 \%$ of patients had some type of complication within 30 days; need for blood transfusion was the most frequent $(53 \%)$, followed by infection (19\%), and wound dehiscence $(12.7 \%)$. The mortality related to surgery was $3.8 \%$. The use of antiplatelet or anticoagulant therapy after cardiac catheterisation was an independent risk factor for increased postoperative morbidity. ${ }^{16}$

In 1991, Fellmeth et al. ${ }^{7}$ described the treatment of a pseudoaneurysm by ultrasound-guided compression. This method has success rates between $75 \%$ and $98 \%$ and low complication rates. ${ }^{17,18}$ However, in most cases, it is a lengthy and painful procedure, and approximately $80 \%$ of cases require 60 minutes of compression. ${ }^{8}$ Moreover, in patients using antiplatelet and anticoagulant agents, pseudoaneurysm recurrence rates can reach up to $30 \% .^{19}$

Ultrasound-guided TI for the treatment of pseudoaneurysm gained prominence after the publications by Liau et al. ${ }^{20}$ and Kang et al., ${ }^{21}$ with success rates of $100 \%$ and $95 \%$, respectively. Subsequently, several studies in the literature reported success rates between $93 \%$ and $100 \% .^{11-15}$ When compared to ultrasound-guided compression, $\mathrm{TI}$ had a higher success rate $(100 \% \mathrm{vs}$. $87 \% ; \mathrm{P}<0.05)$ with lower hospital cost. ${ }^{22}$ Krüger et al. ${ }^{11}$ also observed that the success rates were higher with simple pseudoaneurysms, when compared to the rates of multiloculated pseudoaneurysms (97\% vs. 61\%). However, in the present population, in which $17.5 \%$ of pseudoaneurysms were multiloculated, the success rate was $100 \%$, regardless of the pseudoaneurysm characteristics.

$\mathrm{TI}$ in patients using antiplatelet and anticoagulant agents was also evaluated in some studies. The failure rate is higher in patients with concomitant use of antiplatelet and anticoagulant agents $(6.3 \%$ vs. $1.3 \%$; $\mathrm{P}=0.026) .{ }^{12}$ In a study of 30 patients, of whom 18 were anticoagulated, the success rate was $100 \% .^{23}$ In another study of 274 patients using antiplatelet and/or anticoagulant agents, the success rate with thrombin use was $97 \%{ }^{24}$ In the present study, in which $78.3 \%$ of patients used dual antiplatelet therapy and $56.5 \%$ used associated prophylactic use of heparin at the time of treatment with thrombin, the success rate was $100 \%$.

However, most studies did not specify the number of patients with acute coronary syndrome submitted to $\mathrm{TI}$ for pseudoaneurysm repair. In a Brazilian study of 15 patients treated with $\mathrm{Tl}$, all successful procedures, ten had a diagnosis of acute coronary syndrome at admission. ${ }^{14}$ To date, there have been no studies evaluating the use of $\mathrm{TI}$ only in patients with acute coronary syndrome.

Although rare, the procedure is not free of complications. In a multicenter study in Germany with 595 patients, the incidence of thrombus formation in the femoral artery after $\mathrm{TI}$ was $0.5 \%$, with deep vein thrombosis reported in $0.5 \%$, and pulmonary thromboembolism in $0.2 \%$ of the population. ${ }^{12}$ Ohlow et al. ${ }^{25}$ reported a case of distal limb ischemia after $\mathrm{TI}$ that progressed, requiring amputation of the affected limb. There were no reports of complications in the patients treated with thrombin at the present service. There was only one death due to cardiogenic shock after elective coronary artery bypass grafting, with no causal association with $\mathrm{TI}$.

The present study demonstrated the effectiveness and safety of ultrasound-guided TI for the treatment of femoral artery pseudoaneurysm in patients with acute coronary syndrome. Success was achieved in 100\% of cases, regardless of the pseudoaneurysm complexity and antiplatelet agent use. Additionally, there were no complications related to the use of this therapy.

\section{Study limitations}

This is a pioneering study on the results of $\mathrm{Tl}$ in the treatment of femoral artery pseudoaneurysm in patients with acute coronary syndrome. However, its observational nature, without a control group for comparison purposes, as well as the small number of patients does not allow the drawing of definitive and comprehensive conclusions on the subject; randomized trials with larger numbers of patients are required.

\section{CONCLUSIONS}

The present data suggest that ultrasound-guided $\mathrm{TI}$ is a safe and effective method for the treatment of femoral artery pseudoaneurysm occurring after diagnostic or therapeutic heart catheterisation in patients with acute coronary syndrome.

\section{CONFLICT OF INTEREST}

The authors declare no conflicts of interest. 


\section{REFERENCES}

1. Hessel SJ, Adams DF, Abrams HL. Complications of angiography. Radiology. 1981;138(2):273-81.

2. Katzenschlager R, Ugurlouglu A, Ahmadi A, Hülsmann M, Koppensteiner R, Larch E, et al. Incidence of pseudoaneurysm after diagnostic and therapeutic angiography. Radiology. 1995; 195(2):463-6.

3. Righini MQI, Quéré I, Laroche JP. Treatment of postcatheterization femoral false aneurysms. J Mal Vasc. 2004;29(2):63-72.

4. Hughes MJ, McCall JM, Nott DM, Padley SPJ. Treatment of iatrogenic femoral artery pseudoaneurysms using ultrasoundguided injection of thrombin. Clin Radiol. 2000;55(10):749-51.

5. Lumsden AB, Miller JM, Kosinski AS, Allen RC, Dodson TF, Salam AA, et al. A prospective evaluation of surgically treated groin complications following percutaneous cardiac procedures. Am Surg. 1994;60(2):132-7.

6. Piffaretti G, Mariscalco G, Tozzi M, Rivolta N, Castelli P, Sala A. Predictive factors of complications after surgical repair of iatrogenic femoral pseudoaneurysms. World J Surg. 2011;35(4):911-6.

7. Fellmeth BD, Roberts AC, Bookstein JJ, Freischlag JA, Forsythe JR, Buckner NK, et al. Postangiographic femoral artery injuries: nonsurgical repair with US-guided compression. Radiology. 1991;178(3):671-5.

8. Coley BD, Roberts AC, Fellmouth BD, Valji K, Bookstein JJ, Hye RJ. Post angiographic femoral artery pseudoaneurysms: further experience with US guided compression repair. Radiology. 1995;194(2):307-11.

9. Chatterjee T, Do DD, Kaufmann U, Mahler F, Meier B. Ultrasound guided compression repair for treatment of femoral artery pseudoaneurysm: acute and follow-up results. Cathet Cardiovasc Diagn. 1996;38(4):335-40.

10. Webber GW, Jang J, Gustavson S, Olin JW. Contemporary management of postcatheterization pseudoaneurysms. Circulation. 2007;115(20):2666-74.

11. Krüger $K$, Zähringer $M$, Söhngen $F$, Gossmann A, Schulte $O$, Feldmann $\mathrm{C}$, et al. Femoral pseudoaneurysms: management with percutaneous thrombin injections-success rates and effects on systemic coagulation. Radiology. 2003;226(2):452-8.

12. Hofmann I, Wunderlich N, Robertson G, Kieback A, Haller C, Pfeil W, et al. Percutaneous injection of thrombin for the treatment of pseudoaneurysms: the German multicentre registry. Eurolntervention. 2007;3(3):321-6.

13. Vlachou PA, Karkos CD, Bains S, McCarthy MJ, Fishwick G, Bolia A. Percutaneous ultrasound-guided thrombin injection for the treatment of iatrogenic femoral artery pseudoaneurysms. Eur J Radiol. 2011;77(1):172-4
14. Gioppato S, Munhoz A, Marins M, Conforti TB, Castello Jr HJ Cantarelli MJC, et al. Tratamento percutâneo de pseudoaneurismas por injeção de trombina guiada por ultrassom. Rev Bras Cardiol Invasiva. 2010;18(2):165-70.

15. Miranda FC, Garcia RG, Macedo Filho CL, Mendes GF, Andrade JR, Maurano A, et al. Injeção percutânea de trombina guiada por ultra-som com Doppler colorido para o tratamento de pseudo-aneurismas. Einstein. 2008;6(4):428-33.

16. San Norberto García EM, González-Fajardo JA, Gutiérrez V, Carrera S, Vaquero C. Femoral pseudoaneurysms post-cardiac catheterization surgically treated: evolution and prognosis. Interact Cardiovasc Thorac Surg. 2009;8(3):353-7.

17. Eisenberg L, Paulson EK, Kliewer MA, Hudson MP, DeLong DM Carroll BA. Sonographically guided compression repair of pseudoaneurysms: further experience from a single institution. Am J Roentgenol. 1999;173(6):1567-73.

18. Coley BD, Roberts AC, Fellmeth BD, Valji K, Bookstein JJ, Hye RJ. Postangiographic femoral artery pseudoaneurysms: further experience with US-guided compression repair. Radiology. 1995;194(2):307-11.

19. Dean SM, Olin JW, Piedmonte M, Grubb M, Young JR. Ultrasound guided compression closure of postcatheterization pseudoaneurysms during concurrent anticoagulation: a review of seventy-seven patients. J Vasc Surg. 1996;23(1):28-35.

20. Liau CS, Ho FM, Chen MF, YT Lee. Treatment of iatrogenic femoral artery pseudoaneurysm with percutaneous thrombin injection. J Vasc Surg. 1997;26(1):18-23.

21. Kang SS, Labropoulos N, Mansour MA, Baker WH. Percutaneous ultrasound guided thrombin injection: a new method for treating postcatheterization femoral pseudoaneurysms. J Vasc Surg. 1998;27(6):1032-8.

22. Weinmann EE, Chayen D, Kobzantzev ZV, Zaretsky M, Bass A Treatment of postcatheterisation false aneurysms: ultrasoundguided compression vs ultrasound-guided thrombin injection. Eur J Vasc Endovasc Surg. 2002;23(1):68-72.

23. Lennox AF, Delis KT, Szendro G, Griffin MB, Nicolaides AN, Cheshire NJ. Duplex-guided thrombin injection for iatrogenic femoral artery pseudoaneurysm is effective even in anticoagulated patients. Br J Surg. 2000;87(6):796-801.

24. Schneider C, Malisius R, Küchler R, Lampe F, Krause $K$, Bahlmann $\mathrm{E}$, et al. A prospective study on ultrasound-guided percutaneous thrombin injection for treatment of iatrogenic post-catheterisation femoral pseudoaneurysms. Int J Cardiol. 2009;131(3):356-61.

25. Ohlow MA, Secknus MA, von Korn $H$, Weiss $R$, Lauer $B$ Percutaneous thrombin injection for treatment of iatrogenic femoral artery pseudoaneurysms: a case for caution. Angiology. 2008;59(3):372-5. 